\title{
Using ground-penetrating radar to image previous years' summer surfaces for mass-balance measurements
}

\author{
Jack Kohler, ${ }^{1}$ John Moore, ${ }^{2}$ Mike Kennett, ${ }^{1}$ Rune Engeset, ${ }^{1}$ Hallgeir Elvehøy ${ }^{1}$ \\ ${ }^{1}$ Glacier and Snow Section, NVE (Norwegian Water Resources and Energy Administration), P.O. Box 5091, Maj., 0352 Oslo, Norway \\ ${ }^{2}$ The Arctic Centre, University of Lapland, Box 122, 96101 Rovaniemi, Finland
}

\begin{abstract}
In traditional mass-balance measurements one estimates winter snow accumulation by identifying the depth to the previous summer's snow or ice surface using a snow probe. This is labor-intensive and unreliable for inhomogeneous summer surfaces. Another method is to image internal reflection horizons using a ground-penetrating radar (GPR), which has advantages in speed and areal coverage over traditional probing. However, to obtain quantitative mass-balance measurements from GPR images one needs to convert the time scale to a depth scale, not a straightforward problem. We compare a GPR section with dielectric profiles and visual stratigraphy of three snow cores, manual probings, and previous mass-balance measurements. We relate changes in snow-core dielectric properties to changes in density and to the travel times of reflecting horizons in the GPR section, and correlate some of these reflecting horizons with previous summer surfaces. We conclude that GPR can be used as a complementary tool in mass-balance measurements, giving a wide areal survey of winter accumulation and net balance for preceding years. However, proper calibration is essential for identifying specific surfaces in the radar data.
\end{abstract}

\section{INTRODUCTION}

Each spring, glaciologists engaged in "conventional" massbalance measurements can be found on the surface of their respective glaciers, snow probes in hand, thrusting into the previous winter's snow. Their goal is to estimate winter accumulation by identifying the depth to the previous summer's snow or ice surface (Østrem and Brugman, 1991). Among the disadvantages of manual probing, however, are that it is relatively time-consuming to track an often inhomogeneous layer, that it can be hard work if there are any intervening ice layers, as there often are, and that the presence of other ice layers in the accumulation area often makes it difficult to distinguish the summer layer.

Another method is to image internal reflection horizons using a ground-penetrating radar (GPR), as either an alternative or a complementary method to conventional manual probing. Radar has been used previously to determine accumulation rates by finding datable reflecting horizons in Antarctic firn (Forster and others, 1991; Weertman, 1993; C. Richardson and others, unpublished information) and on temperate glaciers (Holmlund and Richardson, 1995).

However, to obtain quantitative mass-balance measurements from GPR images one needs to convert the timedependent radar return signal to a depth-dependent stratigraphic profile, not a straightforward problem. The complexity of the snow stratigraphy, the sensitivity of the depth-time relationship to changes in density, chemistry, grain-size and water content, and the possibility of phase changes on reflection and interference from nearby reflecting horizons make such conversion difficult.

GPR images of snowpacks are a convolution of the input radar wave with the physical properties of the snow that cause echoes, such as density contrasts or changes in snow

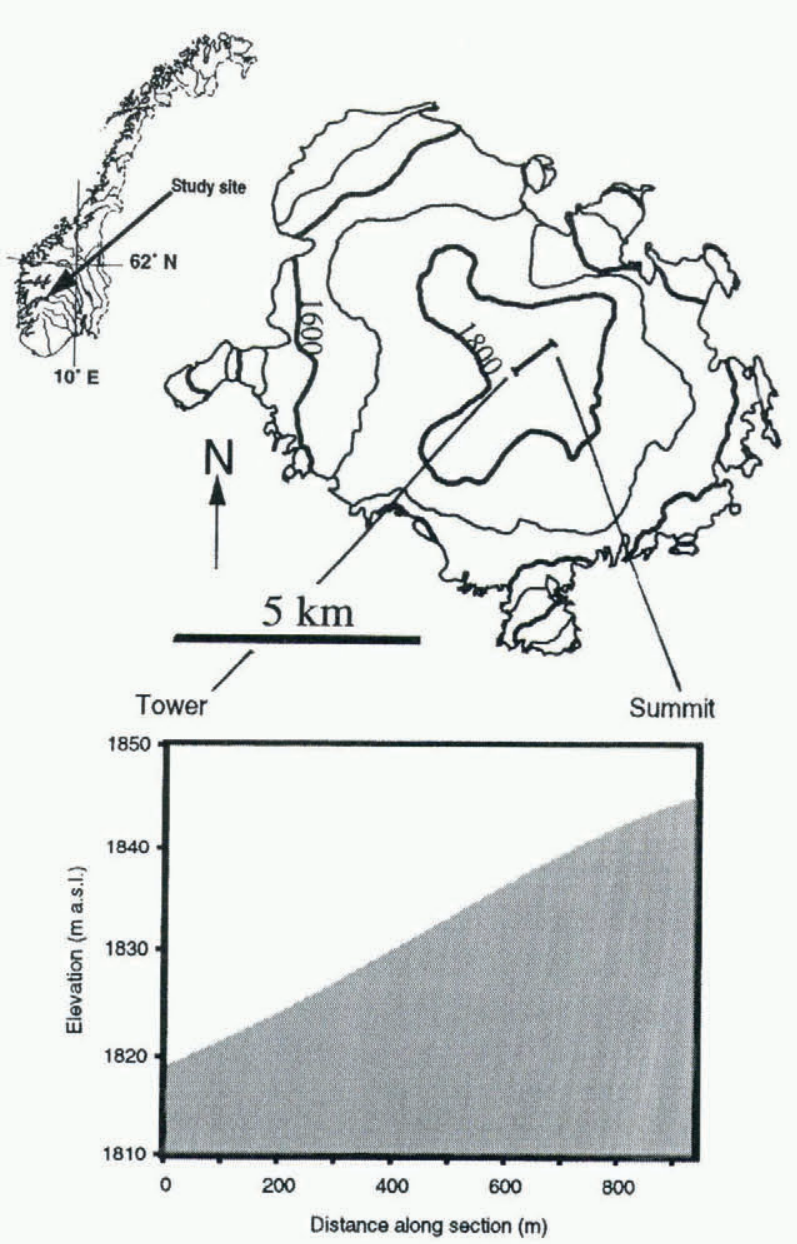

Fig. 1. Location map of Hardangerjøkulen, with elevarion profile along GPR section. 
Table 1. Second column: net balance measurements from tower 2. Density profile measured at tower 2 is used to convert cumulative net balance (third column) tv depths to previous summer surfaces (fourth column). Fifth column: depth to ice lens nearest to the depths in column four. Sixth column: two-way travel-time, based on Equation (1) and the density profile measured on core 1; density below the bottom of the core at $5.6 \mathrm{~m}$ is estimated from previous data (Laumann, 1972)

\begin{tabular}{|c|c|c|c|c|c|}
\hline $\begin{array}{c}\text { Summer surface: } \\
\text { year }\end{array}$ & $\begin{array}{c}\text { Net balance measured at } \\
\text { tower } 2\end{array}$ & $\begin{array}{c}\text { Cumulative net balance at } \\
\text { tower } 2\end{array}$ & Predicted depth at tower 2 & $\begin{array}{c}\text { Depth to corresponding ice } \\
\text { layer in core } 1\end{array}$ & Two-way travel time \\
\hline & mw.e. & mw.e. & $\mathrm{m}$ & $\mathrm{m}$ & ns \\
\hline 1995 & 1.03 & 1.03 & 2.35 & 2.50 & 21.0 \\
\hline 1994 & 0.91 & 1.94 & 3.88 & 3.76 & 36.2 \\
\hline 1993 & 0.74 & 2.68 & 5.11 & 4.88 & 48.7 \\
\hline 1992 & 2.39 & 5.08 & 8.63 & - & 85.7 \\
\hline
\end{tabular}

chemistry. The most rigorous method for interpreting a GPR image would be to do inverse modeling, convoluting the input radar wave with different models of the dielectric properties of the snowpack until a reasonable fit to the radar image was obtained. This is a non-trivial problem, and unlikely to be implemented in operational mass-balance work.

In this paper we adopt a simpler approach. We compare a GPR section made in the firn area of a temperate glacier with dielectric profiles of three snow cores, manual probings to the previous season's summer surface, and previous years' mass-balance measurements. We assume that in the nearsurface each echo is produced by a single reflector, that these reflectors are ice lenses or other sharp density contrasts in the snowpack, that changes in snow chemistry are minor compared to these density changes, and that interference between closely spaced echoes is minimal. If the temperature of the upper firn layers is below freezing (as is often the case at the end of the winter season), the effects of liquid water content on radar wave velocity can be neglected and we can convert the time-dependent radar return signal to a depth-dependent stratigraphic profile using a simple traveltime relation based on the bulk density, as determined from three snow cores. We test our approach by comparing visual observations of ice lenses and continuous permittivity measurements in snow cores to travel times of significant reflecting horizons in the GPR section. We also compare these horizons to the manual probings and to the previous years' mass-balance measurements.

\section{GPR SECTION}

We obtained a GPR section in mid-March 1996 on part of the accumulation area of Hardangerjøkulen, Norway, (Fig. 1). The $930 \mathrm{~m}$ long section (Fig. 2) runs from about $1820 \mathrm{~m}$ a.s.l. at a stake (tower 2) used in the mass-balance

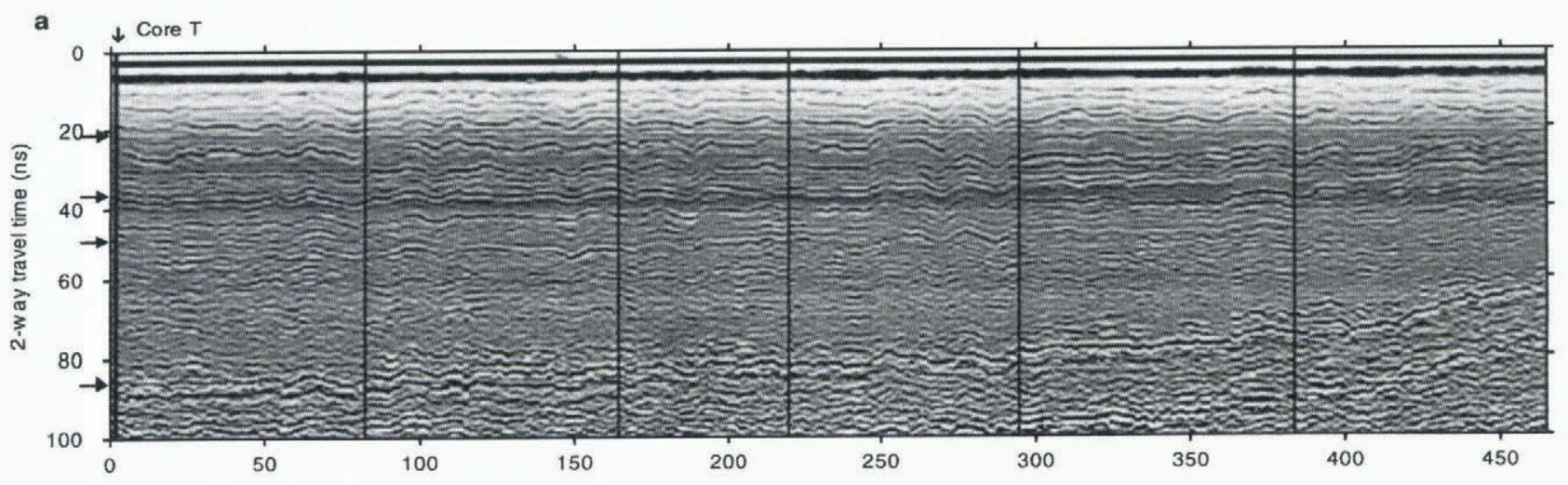

b

$\downarrow$ Core M

Core $\mathrm{S} \downarrow$

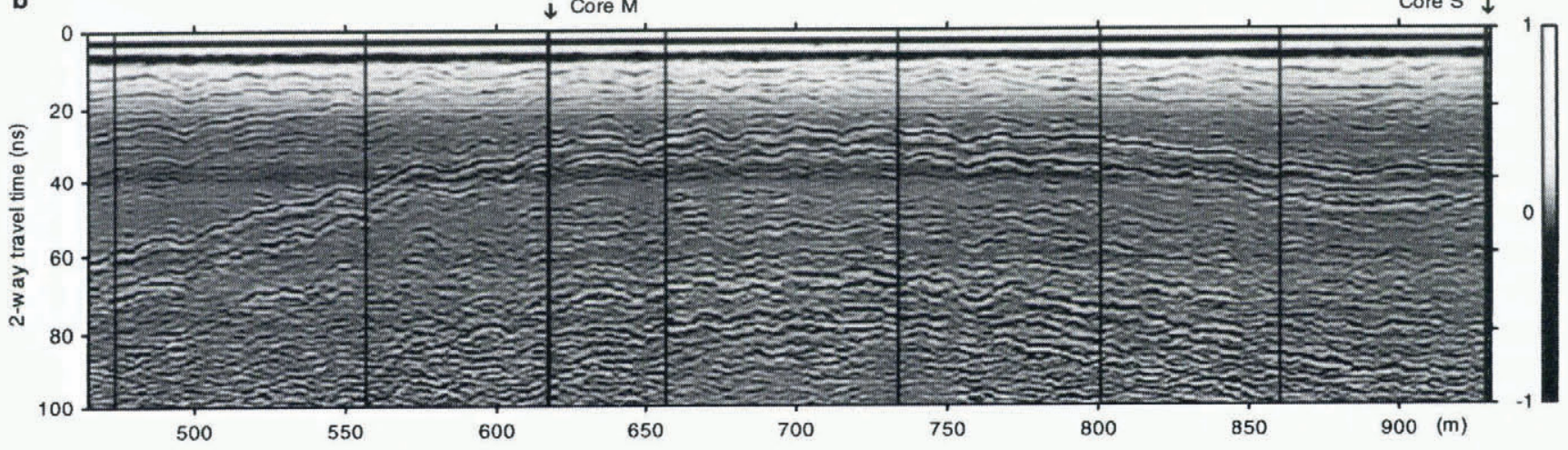

Fig. 2. GPR section, showing manual probing locations (vertical lines) and snow-core locations. Arrows ony axis in (a) show the two-way travel times for the 1995, 1994, 1993 and 1992 summer surfaces predicted from mass-balance measurements at tower 2. 
measurements (Haakensen, 1995) to about $1850 \mathrm{~m}$ a.s.l., near the summit (Fig. 1). The radar used was a SIR-2 GPR with a $500 \mathrm{MHz}$ antenna (made by GSSI, North Salem, $\mathrm{NH}$ ). Scans were taken at about $20 \mathrm{~cm}$ intervals, each with a $100 \mathrm{~ns}$ time window containing 512 samples. A time-varying gain function was used to amplify the signal at depth, but no further processing was performed. The air wave is not removed, disturbing the first $10 \mathrm{~ns}$ of the return, and there is some horizontal banding from the internal circuitry of the radar. The gray-scale for Figure 2 is greatly compressed to emphasize smaller returns as well as large ones.

The main feature of the measured GPR section (Fig. 2a and b) is a series of mostly continuous, subparallel reflecting layers. The layers climb upward toward the summit, indicating an area of lower accumulation. This feature has been observed since mass-balance measurements were initiated (Laumann, 1972), and is the result of local wind patterns.

The large numbers of layers are the result of a wellknown feature of snow stratigraphy on maritime glaciers like Hardangerjøkulen; there are typically several ice layers in a given winter's snowpack formed during periods of warmer weather (Laumann, 1972).

While many of the reflecting layers are easily tracked across the GPR section, giving a relative idea of the accumulation pattern, it is impossible to assign layers to a particular year's summer surface without further information. We turn now to the establishment of the age depth relation and the correlation of ice lenses with the reflecting horizons in the GPR section.

\section{SNOW CORES}

Cores T, M and S (tower, middle, summit) were taken along the section at 5, 345 and $925 \mathrm{~m}$, respectively (Fig. 2). Shallow pits about $1 \mathrm{~m}$ deep were excavated and cores taken from the floors with a SIPRE auger. Core depths reached 5.6, 5.5 and $6.7 \mathrm{~m}$ below the surface. Core quality tended to deteriorate

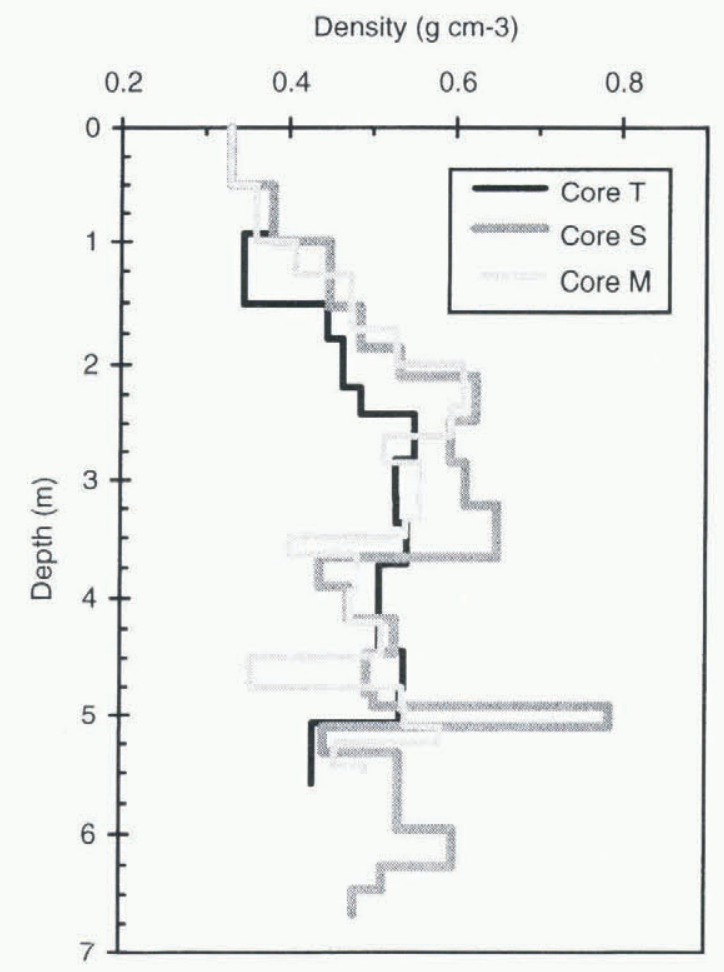

Fig. 3. Density profiles for cores 1-3. at the lower depths due to an unfortunate combination of aged equipment and numerous ice layers.

\section{Stratigraphy and density}

Each core piece was carefully traced onto a piece of paper for estimation of the diameter along the core. The location and thickness of obvious ice lenses in the snow-pit walls and in the snow cores were noted in order to establish a rough stratigraphy. Some of the smaller ice lenses are lost or damaged during the coring process, causing errors in the visual stratigraphy.

The weight, length and average diameter of each recovered core piece were measured to calculate density (Fig. 3). Since individual core pieces vary from 10 to $50 \mathrm{~cm}$ in length, the density so calculated is not fine enough to show individual ice layers. Density in the upper meter is measured using snow tubes in the sides of the pits and is reasonably accurate; below a few meters depth, progressively poorer core quality makes the density measurements less reliable, particularly for cores S and M. We calculate the two-way travel-time vs depth relation using Robin's (1975) expression for dry snow with a geometrical correction for the effect of receiving-transmitting antenna separation:

$$
t=\frac{1}{c}\left\{\left[(1+0.85 \rho) \sqrt{l_{\mathrm{a}}{ }^{2}+4 D^{2}}\right]-l_{\mathrm{a}}\right\},
$$

where $t$ is the two-way travel-time, $c$ is the speed of an electromagnetic wave in a vacuum, $\rho$ is the average snow density between the surface and a depth $D$, and $l_{\mathrm{a}}$ is the antenna separation, in this case, $18 \mathrm{~cm}$. We neglect wave refraction within the snowpack since density changes have a negligible effect on wave path length with such a small antenna separation.

\section{Dielectric profile}

The electrical stratigraphy of the core was measured using a dielectric profiler (Moore, 1993). Conductance and capacitance were measured at $100 \mathrm{kHz}$ using a $4 \mathrm{~cm}$ electrode sampled at $2.5 \mathrm{~mm}$ intervals along the core, giving values of snow conductivity and permittivity, respectively. While the radar frequency of $500 \mathrm{MHz}$ is considerably higher than the dielectric profiling frequency, it is commonly thought that there are no dielectric changes in this frequency range (e.g. Glen and Paren, 1975). This is supported by comparisons between the $100 \mathrm{kHz}$ range and microwave dielectric properties of ice (Moore and Fujita, 1993).

In deep cores, conductivity is of greatest interest as it responds to changes in ice chemical composition (Wolff and others, 1995). In these shallow cores, however, density contrasts should produce the largest changes in dielectric impedance through their effect on permittivity (Glen and Paren, 1975).

Where core quality was good, the measured values of core capacitance and conductance were converted to permittivity and conductivity using a simple geometric air capacitance method (Moore, 1988). Where core quality was poor, we used core diameter data to estimate the fraction of ice and air present between the electrodes and then scaled the measured values appropriately, correcting for the curved geometry of the electrodes. This correction algorithm is imperfect, however, because the core tracings are only two-dimensional, and three-dimensional information 

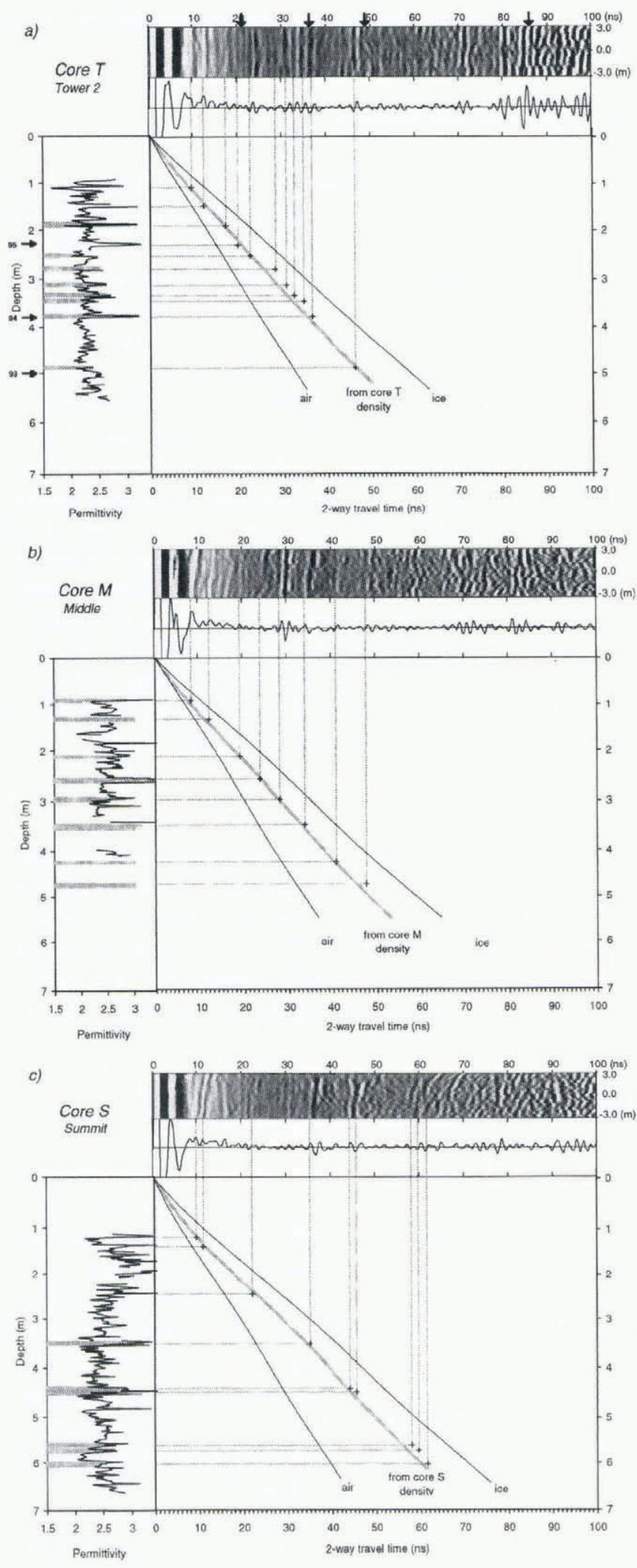

Fig 4. Lefthand plot: permittivity profiles (black lines) and ice lens locations (gray lines). Arrows in (a) show depths to the 1995, 1994 and 1993 summer surfaces, predicted using mass-balance measurements from tower 2. Upper plot: $6 \mathrm{~m}$ wide strips of GPR data, centered on the borehole, and "wiggle" plot for the average radar signal in the center of the strip. Center plot: Lines drawn from ice lenses and significant permittivity peaks intersect lines drawn from the most likely reflecting horizon in the GPR section (crosses). See text for a more detailed explanation of the procedure. Depth vs traveltime relation calculated using Equation (1) and the density profile measured in each snow core (gray line) and for air and ice (black lines).

https://doi.org/10.3189/S0260305500012441 Published online by Cambridge University Press would be necessary to correctly calculate how much ice was between the electrodes.

The lefthand plots in Figure $4 \mathrm{a}-\mathrm{c}$ show the permittivity profiles (black lines) and ice lens locations (gray lines). Core quality was best for core Tand worst for core M. Sections of core where no useful data were obtained are not plotted. The ice lenses shown are at least $1 \mathrm{~cm}$ thick; there were also a few thinner layers, but these are not shown. The ice lenses always correspond closely with parts of the cores having high permittivity, as expected. A value of permittivity of 3.17 corresponds to the "high-frequency limiting" value for solid ice, while a value of 1 would be air. Some parts of the cores have permittivity values higher than 3.17 , which may be a result of the algorithm converting capacitance to permittivity on poor-quality snow-core sections, but also may be due to the $100 \mathrm{kHz}$ measuring frequency being too close to the main relaxation frequency of ice to have been a good measure of the "high-frequency limit". In any case the differences are small.

The upper plots in Figure $4 \mathrm{a}^{-} \mathrm{c}$ show $6 \mathrm{~m}$ wide strips of GPR data centered on the borehole at each of the core sites, and a "wiggle" plot of the radar signal averaged over the centermost $4 \mathrm{~m}$ of each strip. The center plots in Figure $4 \mathrm{a}^{-}$ c show the depth vs travel-time relation calculated using Equation (l) and the density profile measured in each snow core, as well as the depth vs travel-time relation for air and solid ice.

We correlate core measurements with GPR reflecting horizons by drawing lines from ice lenses and significant permittivity peaks and connect to lines drawn downward from the negative dip preceding the first positive peak of the most likely reflecting horizon in the center of the GPR strip. Significant permittivity peaks are defined as consisting of more than three points with values $>2.8$ measured in core pieces that are of reasonable quality. The most likely reflecting horizon is judged from the depth vs travel-time relation for the respective cores. A degree of subjectivity is involved in the process, and the large number of candidate reflecting horizons may make it seem that a good match is always possible. The possibilities are not limitless, however, for the two-way travel time must be intermediate between air and ice, and the slope of a line drawn between successive correlation points must not exceed the speed of light $c$.

The match points in Figure 4 are located, for the most part, reasonably close to the line defined by Equation (1). Indeed, many of the thicker ice lenses are easily associated with the stronger reflecting horizons, even in the absence of a calibrated velocity relation. Places where the correlation is not especially good, at 30-40 ns in Figure 4a for example, are most likely the result of interference from closely spaced ice layers with separation distances that are comparable to the radar wavelength.

Some reflecting horizons in the GPR section have no corresponding ice lens or permittivity peak, and conversely, some ice lenses are associated with weak reflecting horizons. This is not completely unreasonable, for the GPR integrates returns over a large area while the snow core is one sample through a stack of inhomogeneously distributed layers, and the permittivity record is imperfect because of the poor quality. A more comprehensive study would use the results of several snow cores drilled close by one another, something that is worth considering for future work.

We conclude then that ice lenses can, for the most part, be correlated readily with reflecting horizons. But which ice 


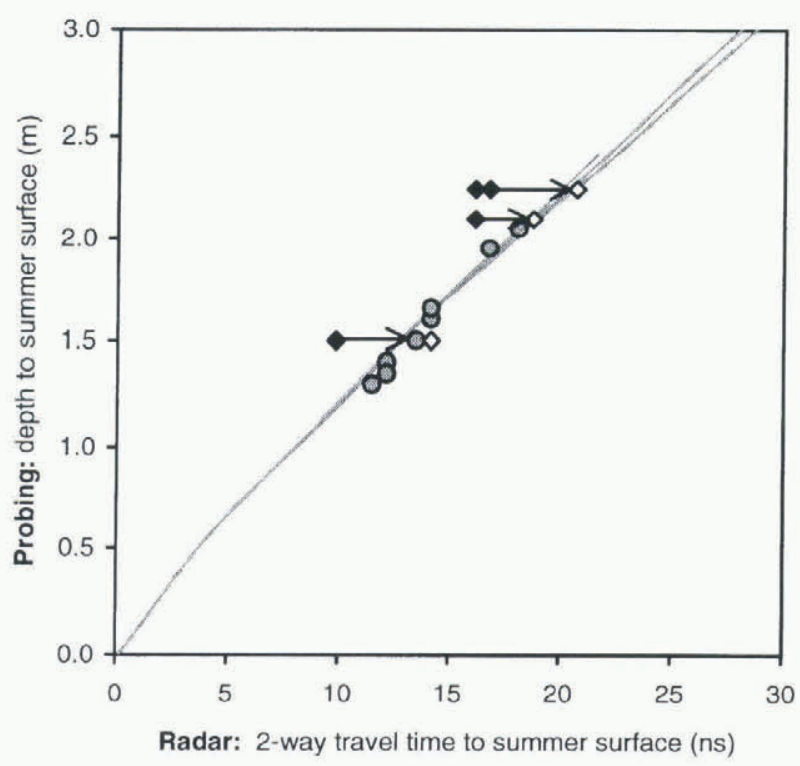

Fig. 5. Sounded depths plotted against two-way travel times to the 1995 summer surface (black circles, black diamonds), and the theoretical relation predicted by Equation (1) for the three snow cores (gray lines). Arrows show change in outlier points (black diamonds) when they are plotted against two-way travel times to the next deepest reflecting horizon (white diamonds), assuming that the probe broke through the 1995 summer surface.

layers and reflecting horizons correspond to summer surface layers? Again, we need further information to answer that question. We turn now to the results of manual probings and a comparison with previous year's mass-balance measurements.

\section{MANUAL PROBINGS}

Conventional probings were made to last summer's snow surface at about $75 \mathrm{~m}$ intervals along the GPR section (Fig. 2). That this was indeed the summer surface rather than an intermediate fall or winter ice layer, of which there were several, was ascertained by comparison with the winter snow depth measured at tower 2 .

Figure 5 shows the manually probed depths plotted against times to the reflecting horizon most likely to correspond with those layers, together with the theoretical relation predicted by Equation (1) for the three snow cores. Most of the data agree well with the theoretical relation. A likely explanation for the outliers is that they are due to the snow probe going through the summer surface to the next deepest ice layer, a common problem with manual probing when the summer surface layer is of variable thickness. This can be demonstrated by replotting the outlier points, assuming that they correspond to the next deepest reflecting horizon in the GPR section; with this modification, the agreement between the manual probings and the radar layer data is excellent (Fig. 5), suggesting that these outliers are indeed due to errors in the manual probing.

\section{MASS-BALANCE MEASUREMENTS}

We use previous years' net balance measurements made at tower 2 (Haakensen, 1995; Elvehøy, unpublished data) to identify deeper layers in the GPR section (Table 1). The cu- mulative net balance in $\mathrm{m}$ w.e. is converted to a snow depth for each summer surface (Table 1), using the core T density profile. This calculation assumes that the water equivalent thickness of a particular balance year does not change as the layer is buried progressively deeper, that is, there is no further gain or loss of ice in a layer. In fact, some net refreezing may occur, but at Hardangerjøkulen this typically amounts to $10 \mathrm{~cm}$ or less (personal communication from $\mathrm{T}$. Laumann, 1996).

The arrows on the lefthand side of Figure 4a show the predicted summer surface depths, while the fifth column in Table 1 gives the depths to the nearest ice lenses. Differences amount to no more than $23 \mathrm{~cm}$, within the limits of error for stake measurements to an uneven snow surface.

The upper arrows in Figure 4a, the arrows on the lefthand side of Figure $2 \mathrm{a}$ and values in the final column of Table 1 are the travel times obtained using Equation (1) and the core Tdensity profile. As with the matching of ice lenses to radar horizons, there are a number of possible horizons to which we can correlate. Nevertheless, it is encouraging that the inferred travel time for the deepest layer at $86 \mathrm{~ns}$ is situated near the reflecting horizon that is both largest in amplitude and most continuous across the GPR section. This is not proof that the 1992 summer surfaces lie at 86 ns; we simply observe that the depth to this layer is consistent with that predicted theoretically.

We reiterate, however, that the correlation of reflecting horizons to past summer surfaces would not be possible without the additional mass-balance data.

\section{CONCLUSION}

Manual probing is time-consuming and often unreliable. Since summer surfaces are spatially inhomogeneous, one might miss a thin part of the summer ice layer when probing, leading to a too deep snow-depth estimate. Comparison of GPR and probing data shows that this is almost certainly the case at Hardangerjøkul. Alter-natively, probing to shallower ice layers formed during the autumn or winter would give too shallow a snow depth. GPR provides a detailed picture of the snowpack, both with depth and laterally, and thus allows continuous tracking of horizons.

However, conversion of the GPR image's time scale to a depth scale is not straightforward, and independent depth measurements to previous summer surfaces are needed to obtain quantitative mass-balance data. GPR is an excellent complement to traditional methods, but cannot replace them without a better understanding of the physical processes that govern radar echoes in the near-surface.

\section{ACKNOWLEDGEMENTS}

We thank P. Holmlund, C. Richardson and an anonymous reviewer for their helpful and insightful comments on the manuscript. We also thank T. Laumann and M. Schlerf for assistance in the field and useful discussions.

\section{REFERENGES}

Forster, R. R., C. H. Davis, T.W. Rand and R. K. Moore. 1991. Snow-stratification investigation on an Antarctic ice stream with an X-band radar system. F. Glaciol., 37 (127), 323-325.

Glen, J.W. and J. G. Paren. 1975. The electrical properties of snow and ice. $\mathcal{F}$. Glaciol., 15 (73), 15-38. 
Haakensen, N., ed. 1995. Glasiologiske undersøkelser i Norge 1992 og 1993. NVE, Norges Vassdrags-og Energiverk. Hydrologisk Avdeling. Publikasjon 08.

Holmlund, P. and C. Richardson. 1995. Tarfala Research Station annual report, 1993-1994. Stockholm, Stockholm University. Department of Physical Geography, 42-43. (Forskningsrapport 102.)

Laumann, T. 1972. Snø, firn og is-en undersøkelse på Hardangerjøkulen. (M.Sc. thesis, Oslo University.)

Moore, J. C. 1988. Dielectric variability of a $130 \mathrm{~m}$ Antarctic ice core: implications for radar sounding. Ann. Glaciol., 11, 95-99.

Moore, J. C. 1993. High-resolution dielectric profiling of ice cores. F. Glaciol., 39 (132), 245-248.

Moore, J. C. and S. Fujita. 1993. Dielectric properties of ice containing acid and salt impurity at microwave and low frequencies. f. Geophys. Res.,
98(B6), $9769-9780$.

Østrem, G. and M. Brugman. 1991. Glacier mass-balance measurements. A manual for field and office work. Saskatoon, Sask., Environment Canada. National Hydrology Research Institute. (NHRI Science Report 4.)

Robin, G. de Q. 1975. Velocity of radio waves in ice by means of a bore-hole interferometric technique. 7. Glaciol., 15(73), 151-159.

Weertman, B. R. 1993. Interpretation of ice sheet stratigraphy: a radio-echo sounding study of the Dyer Plateau, Antarctica. (Ph.D. thesis, University of Washington.)

Wolff, E.W., J. C. Moore, H. B. Clausen, C. U. Hammer, J. Kipfstuhl and K. Fuhrer. 1995. Long-term changes in the acid and salt concentrations of the Greenland Ice Core Project ice core from electrical stratigraphy. 7. Geophys. Res., 100 (D8), 16,249-16,263. 